\title{
Impaired mobility and impaired working capacity among foreign born people and native born Swedes
}

\author{
Sonja Pudaric, Jan Sundquist, Sven-Erik Johansson
}

\begin{abstract}
Objective-The aim of this study is to analyse the influence of country of birth and attained level of education, on impaired mobility and impaired working capacity adjusted for age, sex, and other background variables.

Setting-Sweden.
\end{abstract}

Design-A random sample of 5798 men and 6072 women aged 55-74 years were interviewed face to face by Statistics Sweden 1986-1993. Dependent variable: impaired mobility and impaired working capacity. Independent variables: sex, age, country of birth (Swedes, Finns, Western countries, south Europeans, and all others), attained level of education, marital status, form of tenure, and social network. This study was designed as a cross sectional study. The data were analysed with unconditional logistic regression in main effect models. The results are shown as odds ratios $(\mathrm{OR})$ with $\mathbf{9 5 \%}$ confidence intervals (CI).

Results-In general, poor health, defined as impaired working capacity or impaired mobility, proved to be more frequent among foreign born people and in all socially disadvantaged groups such as those with a low educational status, people renting a dwelling or with a poor social network. Impaired working capacity and impaired mobility were more frequent among female "all others". The impaired mobility among men and women born in south Europe was high with $O R=2.65$ $(\mathrm{CI}=1.34,5.25)$ and $\mathrm{OR}=3.17 \quad(\mathrm{CI}=1.44$, 7.00) in the full model. Men and women from Finland and all other countries had high risks for impaired mobility when adjusted for all background variables. Finnish men and south European women had the highest odds ratios for impaired working capacity. There was a clear gradient between educational status and impaired working capacity, with the highest odds ratios for men and women, 2.39 and 1.92, with a low attained level of education, when adjusting for the independent variables.

Conclusion-Country of birth and educational status are two important independent factors with influence on poor health defined as impaired mobility and impaired working capacity in age 55-74.

(F Epidemiol Community Health 1998;52:34-40)

This paper focuses on the influence of country of birth (Swedes versus foreign born people from Finland, Western countries, south Europe, and all other countries), socioeconomic position, and sociodemographic factors on self reported impaired mobility and impaired working capacity in a random sample of the Swedish population aged 55-74 years.

Immigration to Sweden has increased in the 1990 s mainly because of a wave of refugees at the beginning of the decade and later immigration of relatives. The proportion of foreign born people increases steadily every year from 9.6\% in December 1992 to $10.7 \%$ at the end of 1996 (Statistics Sweden 1993, 1997). The proportion of foreign born people aged 65 and above is steadily increasing from $5.5 \%$ of all foreign born people in 1989 , to $7.2 \%$ in 1994 , and to $13.1 \%$ in 1996. In December 1996, Swedish born people aged 65 and above accounted for $18.0 \%$ of all native born people (Statistics Sweden 1990, 1995, and 1997).

During the boom of the fifties and sixties, Sweden welcomed labour migrants when industry needed labour. Migration from the Scandinavian countries has been free, with a common market since 1954, and is dominated by Finns. Other labour migrants were recruited from rural areas in southern Europe. When the recession came in the late sixties, the Swedish government enacted a law in 1967 requiring a would be immigrant to have a place to live, a job, and a work permit before coming to Sweden. During the seventies, immigration to Sweden changed character as the nonScandinavian labour migration ceased and the non-European immigration of refugees increased steadily.

Activity in an aging population is important associated with health and a longer survival for women but not men. ${ }^{1}$ The Alameda Study showed that needing no assistance, and having no difficulty in mobility/activity or having little or no difficulty in physical performance, high educational level, income above the lowest quintile in 1984, and white ethnicity were associated with successful aging in $1990 .^{2}$ Multiple logistic regression was used in which successful aging in 1990 was regressed on the baseline predictors, as well as on successful aging in 1984, which had a strong association with follow up successful aging. ${ }^{2}$ Walking is the most common form of exercise for aging people $^{3}$ and was associated with successful aging for both men and women in the Alameda study. $^{2}$

Elderly immigrants from Ireland have poorer health than the corresponding group of old people in England. ${ }^{4}$ As far as we know, there are no population based studies focusing on the health of native born elderly and foreign born elderly in a large random sample of a whole 
country in the same way as in this study. Knowledge about aging immigrants is scarce. Early disablement pension was five to six times more frequent in Stockholm county in 1988 among southern European women compared with Swedish women. ${ }^{5}$ Immigrant status and low socioeconomic status were predictors of early retirement pension in a municipality of Southern Sweden. ${ }^{6}$

Gillam has demonstrated the complexity of the association between ethnicity and health and that a focus on cultural differences can conceal social problems such as unemployment and overcrowding. ${ }^{7}$ A Swedish study based on a small random population of 1523 Swedes and foreign born people showed that ethnicity defined as country of birth was an independent important social dimension comparable with social class in relation to self rated illness. ${ }^{8}$ There was a clear segregation in housing and other living conditions between Swedes and foreign born people, where all immigrants, especially Latin Americans refugees, had increased self rated poor health compared with Swedes. ${ }^{9}$

Measurements of morbidity are difficult. One way to obtain information about subjective health (illness) is to use surveys such as in this study. The Gothenburg longitudinal study of people aged 70 showed that foreign born people, 62 persons from Germany, Estonia, and Poland (48\% drop outs) reported poorer health compared with Swedes while there were few differences in objective health between Swedes and foreign born people. ${ }^{10}$ However, in a Swedish follow up study of 39156 persons from 1 January 1979 to 31 December 1993, self reported poor health, was a strong predictor of mortality among men and women aged 25-59 and 60-74, respectively, when controlled simultaneously for age, marital status, education, and form of housing tenure. ${ }^{11} \mathrm{~A}$ longitudinal study from Alameda County ${ }^{12}$ and NHANES-I, a national survey from the USA, ${ }^{13}$ showed that poor self rated health was a strong predictor for mortality.

There is a long tradition of conducting this type of survey in the USA, Sweden, and the UK. To a large extent the same questions have been used in all these surveys, for example, the American Health Interview Survey, the British General Household Survey, and The Swedish Survey of Living Conditions, which started in $1975 .^{14}$ The general purpose of the survey is to obtain an analysis of the distribution of economic resources, health status, and various aspects of the social and work environment in the Swedish population. ${ }^{15}$ The questions were designed to provide objective data about living conditions.

Many studies have repoorted a strong reverse relation between educational status and overall mortality. ${ }^{16}{ }^{17}$ Education has become a commonly used measure of socioeconomic position in epidemiological studies, although other dimensions such as residential area, form of tenure, occupational status are important to explore. ${ }^{18}$ In this study we analyse the relation between education and form of tenure and impaired mobility and impaired working
KEY POINTS

- There was a strong relation between country of birth and impaired mobility and an increased risk for long term illness caused impaired working capacity in people aged 55-74 years.

- Labour migrant men and women born in Finland or in southern Europe, aged 55-74 had increased risks for impaired mobility and impaired working capacity when adjusted for demographic factors, socioeconomic position, and material factors simultaneously.

- There is a strong relation between being a refugee born in Eastern Europe and nonWestern countries in Asia, Africa, and Latin America and impaired mobility and impaired working capacity.

- Older people with a low educational status had the highest odds for impaired working capacity and impaired mobility followed by those with a intermediate educational status.

- Poor social network and renting accommodation were for both aging men and women associated with an increased risk for impaired mobility and working capacity.

capacity. Both variables explore different dimensions of the socioeconomic position while form of tenure also could be used as a material standard measure.

The aim of this study is to analyse the influence of country of birth and attained level of education on impaired mobility and impaired working capacity adjusted for age, sex, marital status, social network, and material standard defined as form of housing tenure. This study included people in the age range 55 to 74 with the objective of obtaining knowledge about health and well being the years before and after retirement.

We hypothesise that country of birth (foreign born people) and low attained level of education are both important independent factors associated with impaired mobility and impaired working capacity.

\section{Methods}

The data were collected by Statistics Sweden. ${ }^{14}$ The interviews were conducted face to face in the homes of the respondents. The Swedish Survey of Living Conditions applies to the whole population in the age bracket 16-84 years, but this study is limited to the ages $55-74$ years and consists of 5798 men and 6072 women. The data were collected during 19861993 and the respondents constituted eight independent simple random samples of the Swedish population. The same questions and the same sampling procedure (simple random sample) were used. The response rate was on average $80 \%$.

DEPENDENT VARIABLES

Impaired mobility

Respondents who could not run 100 metres. 
Table 1 (A) Distribution of impaired mobility and impaired working capacity by sex and the independent variables in ages 55-74, percentages (\%). $n($ men) $=5798 ; n$ (women $)=6072$

\begin{tabular}{|c|c|c|c|c|}
\hline \multirow[b]{2}{*}{ Variable } & \multicolumn{2}{|c|}{ Impaired mobility $\%$} & \multicolumn{2}{|c|}{ Impaired working capacity $\%$} \\
\hline & Men & Women & Men & Women \\
\hline \multicolumn{5}{|l|}{ Age } \\
\hline $55-59$ & 15.8 & 24.8 & 30.3 & 37.3 \\
\hline $60-64$ & 25.4 & 32.2 & 40.8 & 44.7 \\
\hline $65-69$ & 30.3 & 39.5 & 37.2 & 40.7 \\
\hline $70-74$ & 45.0 & 52.8 & 45.6 & 46.1 \\
\hline \multicolumn{5}{|l|}{ Country of birth } \\
\hline Sweden & 28.1 & 36.6 & 37.8 & 41.1 \\
\hline Finland & 41.0 & 41.6 & 53.8 & 50.8 \\
\hline West & 27.2 & 40.3 & 37.0 & 46.7 \\
\hline South Europe & 36.6 & 61.4 & 37.5 & 71.0 \\
\hline All others & 36.1 & 54.1 & 45.4 & 53.5 \\
\hline \multicolumn{5}{|l|}{ Education } \\
\hline$\leqslant 9$ years & 33.4 & 42.1 & 44.3 & 45.4 \\
\hline $10-11$ years & 25.9 & 34.5 & 35.5 & 41.1 \\
\hline$>11$ years & 17.8 & 20.7 & 22.9 & 27.8 \\
\hline \multicolumn{5}{|l|}{ Marital status } \\
\hline Living alone & 35.7 & 43.2 & 43.5 & 45.2 \\
\hline Married/cohabiting & 26.4 & 34.2 & 36.6 & 40.4 \\
\hline \multicolumn{5}{|l|}{ Social network } \\
\hline Poor & 33.7 & 48.4 & 40.5 & 49.1 \\
\hline Good & 27.5 & 35.7 & 37.7 & 41.0 \\
\hline \multicolumn{5}{|l|}{ Housing tenure } \\
\hline Renting & 36.9 & 44.3 & 43.3 & 47.1 \\
\hline Owning & 25.3 & 33.8 & 36.2 & 39.4 \\
\hline
\end{tabular}

Table 1 (B) Distribution of the independent variables by country of birth in ages 55-74, percentages (\%); men

\begin{tabular}{|c|c|c|c|c|c|}
\hline \multirow[b]{2}{*}{ Variable } & \multicolumn{5}{|c|}{ Country of birth } \\
\hline & Sweden & Finland & West & South Europe & All others \\
\hline Number & 5365 & 107 & 169 & 44 & 107 \\
\hline \multicolumn{6}{|l|}{ Age } \\
\hline $55-59$ & 24.4 & 38.3 & 24.3 & 52.8 & 40.0 \\
\hline $60-64$ & 25.6 & 34.7 & 41.7 & 33.3 & 31.3 \\
\hline $65-69$ & 27.2 & 15.2 & 22.0 & 11.1 & 15.6 \\
\hline $70-74$ & 22.8 & 11.8 & 12.0 & 2.8 & 13.0 \\
\hline \multicolumn{6}{|l|}{ Education } \\
\hline$\leqslant 9$ years & 54.2 & 59.1 & 31.5 & 42.2 & 28.6 \\
\hline $10-11$ years & 33.8 & 30.8 & 52.7 & 33.5 & 33.9 \\
\hline$>11$ years & 14.0 & 10.1 & 15.8 & 24.3 & 37.5 \\
\hline \multicolumn{6}{|l|}{ Marital status } \\
\hline Living alone & 23.4 & 26.4 & 25.8 & 9.8 & 28.4 \\
\hline Married/cohabiting & 76.6 & 73.6 & 74.2 & 90.2 & 71.6 \\
\hline \multicolumn{6}{|l|}{ Social network } \\
\hline Poor & 17.7 & 19.2 & 25.3 & 22.9 & 27.6 \\
\hline Good & 82.3 & 80.8 & 74.7 & 77.1 & 72.4 \\
\hline \multicolumn{6}{|l|}{ Housing tenure } \\
\hline Renting & 27.0 & 32.0 & 36.9 & 42.1 & 48.9 \\
\hline Owning & 73.0 & 68.0 & 63.1 & 57.9 & 51.1 \\
\hline
\end{tabular}

Table 1 (C) Distribution of the dependent variables by country of birth in ages 55-74, percentages (\%); women

\begin{tabular}{|c|c|c|c|c|c|}
\hline \multirow[b]{2}{*}{ Variable } & \multicolumn{5}{|c|}{ Country of birth } \\
\hline & Sweden & Finland & West & South Europe & All others \\
\hline Number & 5477 & 242 & 210 & 36 & 102 \\
\hline \multicolumn{6}{|l|}{ Age } \\
\hline $55-59$ & 23.6 & 36.2 & 29.3 & 38.0 & 32.6 \\
\hline $60-64$ & 23.2 & 26.9 & 28.0 & 39.7 & 32.0 \\
\hline $65-69$ & 27.3 & 21.7 & 29.3 & 17.3 & 17.0 \\
\hline $70-74$ & 25.9 & 15.0 & 13.4 & 5.0 & 18.4 \\
\hline \multicolumn{6}{|l|}{ Education } \\
\hline$\leqslant 9$ years & 57.6 & 56.2 & 39.9 & 62.8 & 38.2 \\
\hline $10-11$ years & 31.6 & 38.2 & 44.2 & 25.0 & 37.1 \\
\hline$>11$ years & 10.8 & 5.6 & 15.9 & 12.2 & 24.7 \\
\hline \multicolumn{6}{|l|}{ Marital status } \\
\hline Living alone & 35.5 & 44.0 & 37.1 & 48.7 & 42.8 \\
\hline Married/cohabiting & 64.5 & 56.0 & 62.9 & 51.3 & 57.2 \\
\hline \multicolumn{6}{|l|}{ Social network } \\
\hline Poor & 13.5 & 14.6 & 16.5 & 23.2 & 32.4 \\
\hline Good & 86.5 & 85.4 & 83.5 & 76.8 & 67.6 \\
\hline \multicolumn{6}{|l|}{ Housing tenure } \\
\hline Renting & 34.2 & 38.7 & 40.2 & 61.2 & 56.4 \\
\hline Owning & 65.8 & 61.3 & 59.8 & 38.8 & 43.6 \\
\hline
\end{tabular}

Working capacity

Respondents who reported that long term illness caused impaired working capacity at least to some extent, in working or normal daily activities, were regarded to have impaired working capacity.

\section{INDEPENDENT VARIABLES}

Age, sex, country of birth (Swedes and foreign born people were divided into five groups. Swedes comprised the first group. People born in Finland were in the second group. They could all be characterised as migrant workers. The third group, people born in Western countries (Western Europe (except Finland and southern Europe), USA, Canada, Australia, New Zealand, and Japan) were all labour migrants including certain experts, university students and their families accepted for settlement in Sweden also after 1967. Southern Europeans formed the fourth group. They were migrant workers from rural areas of Greece, Yugoslavia, Italy, Spain, and Portugal. The fifth group, all others, consisted of refugees from Eastern Europe, and from poor countries in Asia, Africa, and Latin America. They come to Sweden during the 1970s and 1980s), marital status (defined as those who were married/cohabiting and those who lived single), attained level of education (the respondents were classified into three groups: (1) primary school ( $\leqslant 9$ years), (2) completed at least two years of high school (10-11 years), (3) completed more than two years of high school (>11 years), material standard (defined as form of housing tenure. The variable was dichotomised into those who rented their flats and all others), and social network (based on the variables neighbour contacts, casual neighbourhood interaction, having a close friend and how often one saw this friend, and also having other friends, with one point for each item, all together a maximum of five points. If the individual scored less than three points the social network was considered as poor).

\section{STATISTICAL METHOD}

The data were analysed with unconditional logistic regression in main effect models. ${ }^{19}$ The results are shown as odds ratios (OR) with $95 \%$ confidence intervals (CI) calculated by the LOGISTIC procedure in SAS. ${ }^{20}$ Age adjusted odds ratios for each of the dependent variables were calculated and a main effect model with the independent variables (separate analyses for women and men) was taken into consideration. The fit of the models was judged from the Hosmer-Lemeshow goodness of fit test. ${ }^{19}$ The models were considered as good if $p>0.05$. A total of 20 first order interactions were simultaneously tested in each of the four final models, but only two were weakly significant, which can be considered to have occurred by chance. The reliability of all dependent and almost all independent measurements has been analysed by the test-retest method with a $\kappa$ coefficient between 0.7 and $0.95 .^{21}$ 


\section{Results}

Table 1(A) gives the distribution of impaired mobility and impaired working capacity by sex and the other independent variables. Impaired mobility was reported by $61 \%$ of the south European women compared with $37 \%$ of the Swedish women. Impaired working capacity was reported by almost two thirds of the south European women compared with $41 \%$ of the native born women. Impaired working capacity and impaired mobility were also more frequent among female "all others" (table 1 ).

Table 1(B) gives the distribution of the independent variables and the number of respondents by country of birth for men. Male refugees from all other countries had the highest share of people with a high attained level of education of all country of birth groups. About one quarter of the men from all other countries lived alone, had a poor social network, and about half of them rented their apartment (Table 1(B)).
Women born in south Europe had the highest share of persons with a low attained level of education and one quarter of them had a poor social network (table 1(C)). Women from all other countries had the highest share of women with a high level of attained level of education and one third of them had a poor social network.

Table 2 gives the age adjusted ORs for each of the independent variables. In Table 3 the full model with estimated ORs for impaired mobility and self reported impaired working capacity is shown. The risk for impaired mobility among men and women born in south Europe was high with $\mathrm{OR}=2.65$ $(\mathrm{CI}=1.34,5.25)$ and $\mathrm{OR}=3.17 \quad(\mathrm{CI}=1.44$, 7.00). Men and women from Finland and all other countries had high risks of impaired mobility when adjusted for all background variables. Finnish men and south European women had the highest ORs for impaired working capacity (table 3 ).

Table 2 Age adjusted odds ratios (OR) with 95\% confidence intervals (CI) for each of the independent variables

\begin{tabular}{|c|c|c|c|c|}
\hline \multirow[b]{2}{*}{ Variable } & \multicolumn{2}{|l|}{ Impaired mobility } & \multicolumn{2}{|c|}{ Impaired working capacity } \\
\hline & Men & Women & Men & Women \\
\hline \multicolumn{5}{|l|}{ Country of birth } \\
\hline Finland & $2.21(1.40,3.50)$ & $1.55(1.11,2.16)$ & $2.11(1.46,3.05)$ & $1.64(1.28,2.09)$ \\
\hline West & $1.11(0.75,1.65)$ & $1.31(0.91,1.89)$ & $1.04(0.77,1.41)$ & $1.31(1.01,1.70)$ \\
\hline South Europe & $2.58(1.27,5.25)$ & $3.65(1.55,8.58)$ & $1.23(0.69,2.20)$ & $3.87(1.93,7.78)$ \\
\hline All others & $1.79(1.12,2.86)$ & $2.47(1.49,4.09)$ & $1.45(1.01,2.10)$ & $1.66(1.14,2.41)$ \\
\hline Sweden & 1 & 1 & 1 & 1 \\
\hline \multicolumn{5}{|l|}{ Education } \\
\hline$\leqslant 9$ years & $2.00(1.72,2.33)$ & $2.04(1.66,2.52)$ & $2.40(1.94,2.989)$ & $1.92(1.62,2.28)$ \\
\hline $10-11$ years & $1.52(1.29,1.78)$ & $1.65(1.32,2.06)$ & $1.73(1.387,2.16)$ & $1.70(1.42,2.03)$ \\
\hline$>11$ years & 1 & 1 & 1 & 1 \\
\hline \multicolumn{5}{|l|}{ Marital status } \\
\hline Living alone & $1.49(1.24,1.80)$ & $1.25(1.05,1.50)$ & $1.34(1.20,1.49)$ & $1.19(0.99,1.44)$ \\
\hline Married/cohabitating & 1 & 1 & 1 & 1 \\
\hline \multicolumn{5}{|l|}{ Social network } \\
\hline Poor & $1.26(1.05,1.51)$ & $1.73(1.47,2.05)$ & $1.10(1.06,1.15)$ & $1.37(1.18,1.60)$ \\
\hline Good & 1 & 1 & 1 & 1 \\
\hline \multicolumn{5}{|l|}{ Housing tenure } \\
\hline Renting & $1.59(1.44,1.75)$ & $1.45(1.19,1.75)$ & $1.29(1.07,1.57)$ & $1.35(1.10,1.65)$ \\
\hline Owning & 1 & 1 & 1 & 1 \\
\hline Number & 5798 & 6072 & 5798 & 6072 \\
\hline Number of cases & 1659 & 2270 & 2217 & 2553 \\
\hline
\end{tabular}

Table 3 Estimated odds ratios for impaired mobility and self reported impaired working capacity by sex with $95 \%$ confidence intervals adjusting for all background variables in main effect models ( $n$ (men) $=5798$ and $n$ (women) $=6072$; logistic regression)

\begin{tabular}{|c|c|c|c|c|}
\hline \multirow[b]{2}{*}{ Variable } & \multicolumn{2}{|l|}{ Impaired mobility } & \multicolumn{2}{|c|}{ Impaired working capacity } \\
\hline & Men & Women & Men & Women \\
\hline \multicolumn{5}{|l|}{ Country of birth } \\
\hline Finland & $2.06(1.33,3.20)$ & $1.45(1.06,1.98)$ & $1.97(1.28,3.04)$ & $1.54(1.16,2.06)$ \\
\hline West & $1.11(0.76,1.62)$ & $1.32(0.90,1.84)$ & $1.09(0.76,1.56)$ & $1.31(0.96,1.79)$ \\
\hline South Europe & $2.65(1.34,5.25)$ & $3.17(1.44,7.00)$ & $1.29(0.65,2.59)$ & $3.51(1.56,7.91)$ \\
\hline All others & $1.91(1.21,3.00)$ & $2.43(1.51,3.90)$ & $1.71(1.10,2.67)$ & $1.68(1.08,2.62)$ \\
\hline Sweden & 1 & 1 & 1 & 1 \\
\hline \multicolumn{5}{|l|}{ Education } \\
\hline$\leqslant 9$ years & $1.97(1.60,2.44)$ & $2.06(1.65,2-58)$ & $2.39(1.97,2.90)$ & $1.92(1.57,2.34)$ \\
\hline 10-11years & $1.54(1.23,1.92)$ & $1.68(1.33,2.13)$ & $1.74(1.42,2.14)$ & $1.70(1.38,2.09)$ \\
\hline$>11$ years & 1 & 1 & 1 & 1 \\
\hline \multicolumn{5}{|l|}{ Marital status } \\
\hline Living alone & $1.34(1.16,1.56)$ & $1.19(1.04,1.37)$ & $1.22(1.06,1.41)$ & $1.14(1.01,1.29)$ \\
\hline Married/cohabiting & 1 & 1 & 1 & 1 \\
\hline \multicolumn{5}{|l|}{ Social network } \\
\hline Poor & $1.18(1.01,1.38)$ & $1.62(1.36,1.92)$ & $1.05(0.90,1.22)$ & $1.29(1.10,1.52)$ \\
\hline Good & 1 & 1 & 1 & 1 \\
\hline \multicolumn{5}{|l|}{ Housing tenure } \\
\hline Renting & $1.43(1.25,1.65)$ & $1.31(1.15,1.51)$ & $1.20(1.04,1.37)$ & $1.24(1.10,1.41)$ \\
\hline Owning & 1 & 1 & 1 & 1 \\
\hline \multicolumn{5}{|l|}{ Goodness of fit test } \\
\hline$\chi^{2}$ & 5.0 & 10.5 & 3.9 & 3.4 \\
\hline $\mathrm{df}$ & 8 & 8 & 8 & 8 \\
\hline $\mathrm{p}$ value & 0.76 & 0.23 & 0.87 & 0.91 \\
\hline
\end{tabular}


Men and women with a low educational level had the highest ORs for impaired mobility with $\mathrm{OR}=1.97 \quad(\mathrm{CI}=1.60,2.44)$ and $\mathrm{OR}=2.06$ $(\mathrm{CI}=1.65,2.58)$ respectively when adjusting simultaneously for age, country of birth, marital status, form of tenure, and social network (table 3). There was also a clear gradient between attained level of educational status and impaired working capacity, with the highest ORs for men and women, 2.39 and 1.92 , with a low attained level of education. The ORs were still high for men and women with an intermediate educational level although ORs decreased to 1.74 and 1.70 respectively in the final model (table 3 ).

\section{Discussion}

The main finding in this study, based on a random sample of 11870 men and women aged $55-74$, is a strong relation between country of birth, especially male and female labour migrants born in Finland, southern Europe or refugees born in Eastern Europe and poor countries in Asia, Africa, and Latin America, and impaired mobility and impaired working capacity when adjusted for the other independent variables. Furthermore, there was a graded association between educational status and impaired mobility and impaired working capacity in the final models, so that people with a low attained level of education had the highest ORs for impaired working capacity and impaired mobility, followed by those with a intermediate educational status.

The advantages of this study were the well defined study population, the comparatively few drop outs, with a response rate of about $80 \%$. Another strength of this study was the focus on a large random sample of the Swedish population. In this study it was possible to control simultaneously for variables such as age, country of birth, educational level, marital status, social network, and form of tenure. All these variables are important for the well being in an aging population. The number of cases was large enough to permit analysis of data separately by sex and two age groups. The construction of the social network index was in agreement with other studies on this topic. $^{22-24}$

There are some important limitations to this study, however, which we should emphasise. One example is the opinion that self rated data are subjective and not an objective measure of health status like for example, death rates or health examinations. However, epidemiological studies from Alameda County, ${ }^{11}$ USA, ${ }^{12}$ and Sweden ${ }^{13}$ showed that self reported ill health was a powerful predictor of mortality. Other studies have been focused on particular dimensions of the concept of self rated health such as functional ability among elderly people. ${ }^{25}{ }^{26}$ The findings of a strong association between increasing age and impaired mobility and impaired working capacity for men and women concurred with a four year follow up study in France of 645 people aged 60 and over. Self rated poor health and disability were associated with ORs of 3.9 and 7.8 respectively for mortality. ${ }^{27}$ The present study, however, did not focuse on mortality among older people. This type of survey has a long tradition and experience, and the questions were well validated. It is of course important not to draw causal conclusions from a cross sectional study because it is not possible to exclude an opposite direction of causality. Selection might be caused by manifold factors. It is difficult to exclude a reverse relation between the analysed independent variables and working impairment.

Another problem that we will emphasise is the use of rather large and very heterogeneous foreign born groups. People born in Western countries consist of many different groups of people with Danes, Norwegians, Germans, and North Americans as the largest groups, but they also share similarities, such as the Western lifestyle. This group has many cultural similarities with Swedish people, which might be an explanation for the finding of no differences between these groups in ORs for impaired mobility and impaired working capacity.

The finding that an aging population of refugees from all other countries has such a high risk of impaired mobility and impaired working capacity when adjusting for age, social class, and the other sociodemographic and socioeconomic variables is important and alarming. This very heterogeneous group of foreign born people came as refugees to Sweden from Hungary and Czechoslovakia 1956 and 1967 respectively, from Poland during the 1980s, from Chile, Uruguay and Argentina between 1973 and 1979, from Central America during the 1980s, and from the war in Eritrea and Ethiopia the first large scale migration of refugees from Africa to Sweden (about 11000 since the end of the 1970s). Between 1988 and 1996, 9000 refugees came from Somalia, and from Iran, Iraq, and Lebanon came, during the 1980s, about 80000 refugees who received residence permits. The only thing they share is a history of violent forced migration and a greater cultural distance than other groups of foreign born people. Furthermore, in this study it was shown that they had a higher attained level of education than Swedes in the same age. Many of them have faced during the 1990s increasing unemployment and discrimination during the economical crises in Sweden. All these factors might act as negative psychosocial stressors with negative influence on health.

The finding of high ORs for south European labour migrants might be explained by the hard work in Swedish industry and low status jobs. There were from the beginning healthy migrant workers who were recruited actively by Swedish enterprises during the 1950s and 1960 s. It was probable that ill health was a barrier to immigration during that period. The high ORs for impaired mobility and working impairment for Finns might be explained by selection and by the fact that migration to Sweden is without barriers so unhealthy labourers could move. Finns have also worked hard in Swedish factories with negative influence on their health. There is a cultural 
distance and language barrier between Sweden and Finland despite a common history and a geographical closeness.

As far as we know, there are no comparable studies focusing on disability among foreign born elderly people and native elderly people adjusting for educational status in the same study. The risk for impaired mobility or impaired working capacity increased more than threefold within the group of aging foreign born people with a low educational level. We argue that both country of birth and educational status are two separate forces that influence the health of an aging population. Longstanding health problems created by a lifetime of low status jobs and poor living conditions add to poor integration.

With regard to elderly immigrants, their role in the family is extremely important. In their countries of origin it may be natural to live in an extended family together with the children and their families. Old people are respected and they give advice to their children, for example, in matters of child rearing. They are usually economically dependent on the children. In Sweden their role is completely changed: they are no longer economically dependent on their children (because of the right to social assistance or a pension). They have a flat of their own and some elderly people do not see their children as often, because they are either studying or working. The grandchildren attend kindergarten or school and the elderly can feel completely neglected. The new situation is often very difficult to handle and it is conceivable that this can have a negative influence on health.

Differences in health beliefs, life experiences, language, educational levels, kin linkages, acculturation stress, and reasons for being in Sweden among longstanding immigrants, refugees, and recent refugees alike are important factors to understand when providing care for the Swedish aging population. All these factors may serve as a barrier between the primary care physician, the district nurse, and the aging immigrant.

The findings in this study agreed with a Danish study that analysed the health and functional status of elderly Turkish immigrants in Copenhagen. ${ }^{28}$ Only one third of the respondents reported having no chronic illness, while chronic arthritis was mentioned most frequently. Almost two thirds of the Turkish immigrants reported having pains in their locomotor systems. Only 39 of 116 respondents were able to perform all 11 daily activities investigated. ${ }^{28}$ However, a study in Leicester, in the UK, found no differences between elderly Asians and British elderly in levels of incapacity, but few of the Asians were aware of the health services available to them. ${ }^{29}$

This study, based on a large random sample of the Swedish population aged 55-74 years, has shown that elderly immigrants especially those from Finland, southern Europe, and refugees from Eastern Europe and poor non-European countries together with people renting a dwelling, those with low educational status or those with a poor social network had an increased risk of impaired mobility and impaired working capacity. Some other surveys $^{1-3}$ have observed the importance of activity as a factor associated with well being and longer survival in an aging population. As a result, our research shows that country of birth and educational status are two important independent social factors that have an influence on poor health. Studies dealing with elderly and especially elderly immigrants are few, and our knowledge about their situation is far from sufficient. Further research and analysis of the different factors that influence health and living conditions within this steadily growing population group is necessary.

Funding: this work was supported by grants from The Council for Health and Health Care Research, Lund/Malmö, Swedish Medical Research Council grant no K97-21P-11333-01A Conflicts of interest: none.

1 Iwarsson S, Isacsson Å, Persson D, Scherstén B. Occupation and survival: A 25-year follow-up study of an ageing Swedish population. Am $\mathcal{F}$ Occup Ther (in press)

2 Strawbridge WJ, Cohen RD, Shema SJ, Kaplan GA. Successful ageing: predictors and associated activities. $\mathrm{Am}$ 7 Epidemiol 1996;144:135-41.

3 Suter E, Marti B, Gutzwiller F. Jogging or walkingcomparison of health effects. Ann Epidemiol 1994;4:375-

4 Greenslade L, Pearson M, Madden M. Irish migrants in Britain. Socio-economic and demographic conditions. Occasional papers in Irish studies No3. Liverpool: University of Liverpool, 1991

5 Statens offentliga utredningar 1989:111. Invandrare $i$ storstad. (Immigrants in the city). (In Swedish.)

6 Edén L, Ejlertsson G, Lamberger B, et al. Immigration and socio-economy as predictors of early retirement pensions. Scand F Soc Med 1994;22:187-93

7 Gillam SJ, Jarman B, White P, Law R. Ethnic differences in consultation rates in urban general practice. BMF 1989; 299:953-7.

8 Sundquist J. Ethnicity, social class and health. A populationbased study on the influence of social factors on self-reported illness in 223 Latin American refugees, 333 Finnish and 126 South European labour migrants and 841 Swedish controls. Soc Sci Med 1995;40:777-87.

9 Sundquist J. Living conditions and health. A populationbased study of labour migrants and Latin American refugees in Sweden and those who were repatriated. Scand f Prim Health Care 1995;13:128-34.

10 Waern E, Steen B. Health compared in immigrant vs. Swedish retirees; the greatest differences subjective in nature (In Swedish with an English summary). Läkartidningen 1994; 91:515-18

11 Sundquist J, Johansson S-E. Self reported poor health and low educational level predictors for mortality: a population based follow up study of 39156 people in Sweden. 7 Epidemiol Community Health 1997;51:35-40.

12 Kaplan GA, Camacho T. Perceived health and mortality: a nine-year follow-up of the Human Population Laboratory nine-year follow-up of the Human Population

13 Idler EL, Angel RJ. Self-rated health and mortality in the NHANES-I - epidemiologic follow-up study. Am f Public Health 1990;80:446-52.

14 The Swedish Survey of Living Conditions. Design and Method. Statistics Sweden, 1996.

15 Thorslund M, Wärneryd B. Methodological research in the Swedish surveys of living conditions. Soc Indicators Res 1985;16:77-95.

16 Marmot MG, Smith GD, Stansfeld S, et al. Health inequalities among British civil servants: the Whitehall II study. ties among British civil serve

17 Pappas G, Queen S, Hadden W, et al. The increasing disparity in mortality between socioeconomic groups in the United States, 1960 and 1986. N Engl F Med 1993;329: 103-9.

18 Liberatos P, Link B, Kelsey J. The measurement of social class in epidemiology. Epidemiol Rev 1988;10:87-121.

19 Hosmer DW, Lemeshow S. Applied logistic regression. New York: John Wiley, 1989.

20 SAS Institute Inc. SAS/STAT. Guide for personal computers, Version 6 ed. Cary NC: SAS Institute Inc, 1987

21 Wärneryd B. Levnadsförhållanden. Aterintervjustudie $i$ undersökningen av levnadsförhållanden (ULF) 1989. (Living conditions. Reinterviews in ULF 1989.) In Swedish. Appendix 12, 1991. Statistics Sweden.

22 Hansson BS. Social network, social support and health in elderly men. A population study (dissertation). Malmö: University of Lund, 1988.

23 Östergren PO. Psychosocial resources and health. With special reference to social network, social support and cardiovascular disease (dissertation). Malmö:University of Lund. 
24 Sundquist J, Johansson S-E. The influence of exile and repatriation on mental health and physical health. A population-based study. Soc Psychiatry Psychiatr Epidemiol 1996;31:21-8.

25 Idler EL, Kasi SV, Lemke JH. Self-evaluated health and mortality among the elderly in New Haven, Connecticut, and Iowa and Washington Counties, Iowa, 1982-1986. Am F Epidemiol 1990;131:91-103.

26 McCallum J, Shadbolt B, Wang D. Self-rated heath and survival: A 7-year follow-up study of Australian elderly. Am f Public Health 1994;84:1100-5.
27 Grand A, Grosclaude P, Bocquet H, Albarede JL. Disability, psychosocial factors and mortality among the elderly in a rural French population. F Clin Epidemiol 1990;43: $773-82$.

28 Lewinter M, Kesmez SS, Gezgin K. Self-reported health and function status of elderly Turkish immigrants in Copenhagen, Denmark. Scand F Soc Med 1995;21:15963.

29 Donaldson LJ. Health and social status of elderly Asians: a community survey. BMF 1986;293:1079-82. 